\title{
Reducing HIV Risks Among Active Injection Drug and Crack Users: The Safety Counts Program
}

\author{
Mary Jane Rotheram-Borus · Fen Rhodes • \\ Katherine Desmond · Robert E. Weiss
}

Published online: 11 September 2009

(C) The Author(s) 2009. This article is published with open access at Springerlink.com

\begin{abstract}
The efficacy of Safety Counts, a CDC-diffused intervention, was reanalyzed. In a quasi experimental, cross-over design, injection drug users (IDU) and crack users in two neighborhoods were assigned by neighborhood to receive individual Voluntary HIV Counseling and Testing or Safety Counts and $78 \%$ were reassessed at 5-9 months. Drug users in the Safety Counts program reported significantly greater reductions in risky sex, crack and hard drug use, and risky drug injection. The more sessions of Safety Counts attended, the greater were the reductions in risky acts. Different analytic decisions result in very different findings for the same intervention. Safety Counts is an effective intervention for IDU and crack users. Analytic decision of intervention outcomes is highly related to evaluations of an intervention's efficacy.
\end{abstract}

Keywords HIV - Risk reduction · Drug use - IDU · VCT

\section{Introduction}

Injecting drug users (IDU) and crack users remain at highrisk for HIV in the United States, especially on the East

Electronic supplementary material The online version of this article (doi:10.1007/s10461-009-9606-2) contains supplementary material, which is available to authorized users.

M. J. Rotheram-Borus · F. Rhodes · K. Desmond - R. E. Weiss Center for HIV Identification, Prevention, and Treatment Services, University of California, Los Angeles, CA, USA

M. J. Rotheram-Borus ( $\square)$

UCLA, 10920 Wilshire Blvd., Suite \#350, Los Angeles, CA 90024-6521, USA

e-mail: Rotheram@ucla.edu
Coast [1]. A recent study estimated that there are over 1.8 million IDU in the US, of whom $16 \%$ are HIV+ [2]. Nearly a quarter of currently prevalent HIV cases are attributable to injection drug use or both IDU and male-tomale sexual contact [3]. Concurrently, there are 1.5 million crack users [4], each having a threefold risk of acquiring HIV [5]. Among drug users, HIV risk emerges not only from drug use (i.e., by sharing needles), but also from sexual behaviors [6]. Therefore, it is critical to design and evaluate evidence-based interventions for IDU and crack users. This article re-evaluates the efficacy of Safety Counts, an intervention to reduce both drug and sexual risk among serious drug users.

Needle exchange and methadone maintenance are two effective strategies for reducing HIV risk for IDU [7]. However, despite multiple scientific reviews on its efficacy, most communities in the US do not have access to needle exchange and there are many parts of the world without such access. Given the political realities of acceptable treatments, this study examines an intervention strategy built concurrently with the street-outreach models of the AIDS Community Demonstration Projects [8].

Drug use is concentrated within specific neighborhoods [1], leading consequent HIV risk to be closely linked to geography [9]. Within neighborhoods with high drug use, there are local "hang-out" sites that are frequented by drug users (shooting galleries, squats). Coincident with drug use and HIV risk, drug-infested neighborhoods have high rates of sexually transmitted diseases and crimes. Because of this geographic concentration, street outreach prevention strategies are desirable [10, 11]. By intervening in neighborhoods with high rates of drug use, it is easier and more efficient to target prevention resources, maximizing the cost-effectiveness of prevention funding. Simultaneously, there are likely to be spill-over benefits from interventions 
that concentrate on neighborhoods: peers and social networks exert a strong influence on individuals' high-risk behaviors [12-14].

Street outreach workers can contact drug users in their local hang-outs to deliver HIV prevention messages, both about reducing drug use and increasing condom use. Outreach workers can also facilitate the engagement of drug users into ongoing group and community activities, increasing the exposure to prevention messages, increasing the practice of new behaviors, and building positive social networks. Street-based recruitment and prevention strategies address both the physical and the social dimensions of drug abuse [10] and require that evaluations be based upon interventions delivered at the level of the site, even if tailored to the individual $[15,16]$.

This study implemented a prevention program for streetbased drug users, called Safety Counts. Drug users do not usually access health services or seek care at institutions such as schools, churches, or community centers [13]. Therefore, Safety Counts built on a street outreach approach. The intervention was based on several related theories of behavior change, with the Transtheoretical Stages of Change Model of Prochaska and DiClemente [17, 18] forming the core framework. The intervention also drew on behavior change principles and techniques articulated by social cognitive theories [19-21]. Further information about the Safety Counts intervention can be found in the Program Implementation Manual [22] and an earlier article by Rhodes and Humfleet [23].

Following the protocol of the National Institute on Drug Abuse (NIDA) Cooperative Agreement, this study used the NIDA Standard Intervention for drug users [24] as the control condition. Labeled as VCT in this paper, the control condition delivered a didactic voluntary counseling and testing program over two sessions, in order to inform individuals regarding their HIV serostatus and to motivate them to reduce existing sexual risk acts. The enhanced intervention, Safety Counts, included the VCT sessions plus street outreach, skills-building workshops, individual counseling, and social events. Based on these components and the social cognitive theoretical models common to evidence-based interventions [25], the 7-session Safety Counts Program was delivered to neighborhood drug users. Both self-report and urine screens for active drug use were utilized as outcome measures for the intervention.

Hershberger and colleagues evaluated the Safety Counts intervention in this journal in 2003, finding few significant outcomes of the Safety Counts intervention compared to the standard VCT condition. Our analyses adopt a different perspective towards the data. The prior analyses emphasized as-treated comparisons of compliers in each condition (although intent-to-treat results were presented in the text as well). Those who did not complete the full intervention schedule were discarded from the primary analyses. A key difference between that paper and the present one is our emphasis on intent-to-treat comparisons of those assigned to the VCT control condition and those assigned to Safety Counts.

Beyond the difference in emphasis, the determination of which potential participants to include in the intent-to-treat analyses was not the same in the two studies. In the present study, completion of the NIDA Standard Intervention (attending two sessions) was a criterion for eligibility, and we excluded individuals who did not complete both sessions. In addition, we excluded from analysis those who reported lengthy incarcerations at either the baseline or follow-up assessment, as that reduces the individual's behavioral autonomy. The Hershberger et al. analyses did not make these exclusions.

Another difference between the two studies is that we analyzed the data using some additional outcome markers. The authors of the prior paper analyzing Safety Counts chose several dichotomous outcome measures such as any sexual activity or not, any unprotected sex or not, multiple partners or not, using crack or not, and any injection drug use or not. They also measured selected risky behaviors as percentages: percent of times injected with dirty works, percent of times used condoms. We analyzed a subset of the dichotomous outcome measures from the prior study, with some modifications to definition or analytic method.

However, in addition to these measures, we also used count measures of how frequently the behaviors were practiced, such as number of times injecting (also used in the prior study), number of times using dirty works, number of times using crack, number of times having sex, and number of unprotected sexual risk acts. We did not use outcomes expressed as percentages. We believe that counts provide a useful measure of absolute risk that is superior to percentages. In the case of condoms, for example, count measures capture frequency of sexual activity, as well as relative frequency of condom use. A person using condoms 30 times out of 60 is at greater risk than a person using condoms two times out of four, yet a dichotomous indicator of practicing unsafe sex, or a percentage measure of condom use would not differentiate between these two individuals.

We also chose different methods to analyze the frequency measures. Data plots showed that these measures were not normally distributed, but in fact followed a Poisson distribution. We therefore used random effects models assuming a Poisson distribution for count variables. We believe that this analytic method provides a better fit to the data than did the methods used by the authors of the prior published analyses. For frequency measures, they used a two-way ANOVA approach, which assumes that variables follow a normal distribution. This was not the case for the count (times injected) or percentage variables 
examined in that study. We feel that the choice of appropriate sample and outcome measures in conjunction with correct statistical methods will provide a more accurate evaluation of the actual intervention impact.

\section{Methods}

Sites

Seventeen ZIP codes were identified, within the greater Los Angeles, California metropolitan area, that were anticipated to be similar in ethnic composition and socioeconomic status. The ZIP codes were expected to have many drug users based on having high rates of drug-related deaths, arrests, arrestees with positive drug screening cases of HIV and AIDS, drug-related emergency room admissions and drug intake data and sexually transmitted diseases. From government data sets and existing research projects ongoing in the 17 ZIP codes, two sets of three contiguous ZIP codes

Table 1 Characteristics of the neighborhoods from which participants were recruited

\begin{tabular}{lll}
\hline & Site A & Site B \\
\hline Total population & 125,014 & 176,941 \\
Ethnicity & & \\
White & $36.9 \%$ & $26.9 \%$ \\
Black & $15.9 \%$ & $20.3 \%$ \\
Hispanic* & $46.1 \%$ & $44.9 \%$ \\
Asian & $12.6 \%$ & $19.7 \%$ \\
Median age (years) & 27.5 & 27.6 \\
Foreign born & $35.9 \%$ & $34.8 \%$ \\
Non-English speaking homes & $55.2 \%$ & $57.9 \%$ \\
Average family size (persons) & 3.7 & 4.0 \\
Median household income & $\$ 25,860$ & $\$ 32,565$ \\
Below poverty line & $34.5 \%$ & $24.6 \%$ \\
\hline
\end{tabular}

* Hispanic_of "any race" and therefore reflected in other groups were identified that were similar in the number of anticipated drug users and in the types of drugs being used (details available upon request). Each site consisted of about 50,000 households of about the same size, age, and ethnicity. Table 1 describes the demographics of the two sites. After Site A and Site B were identified, the sites were randomly assigned to receive either the VCT or the Safety Counts intervention in the first phase of the study. In the second phase, each site received the alternative intervention condition. Figure 1 outlines the recruitment and assignment to intervention condition that took place in Sites A and B over the 3.5 years of the study, during 1992-1995.

\section{Participants}

All drug users hanging out in either Site A or Site B were potentially eligible for participation. Most participants lived in the ZIP codes in which they were recruited, although some participants hung out frequently in the study sites with drug abusing peers, but actually lived in nearby areas. Outreach workers visited common hang-out sites and screened all persons at the site individually. If the potential participant reported IDU or crack use in the last 30 days, he or she was taken to a field office where an interviewer conducted the baseline interview. In order for potential participants to be eligible for the study, their self-reported crack or injection drug use had to be confirmed, either by visible track marks or positive urine tests for opiates or cocaine. Upon completion of the baseline interview, all participants were offered VCT, and those who completed both sessions were enrolled in the study. All participants testing HIV+ were offered an additional counseling session focused on linking participants to health and mental health care.

As outlined in Fig. 1, in the first phase of the study, all eligible participants in Site A next received the Safety Counts intervention; those in Site B received no additional intervention beyond the VCT. In the second phase, a new wave of participants was recruited; new participants in Site
Fig. 1 Study design assignment by neighborhood, with crossover. Each site (neighborhood) comprised three contiguous ZIP codes. Participants enrolled in Phase 2 are new to the study (cross-over is by neighborhood, not individual)

\begin{tabular}{|l|l|l|l|l|l|l|l|l|l|l|l|l|l|}
\hline $\begin{array}{c}\text { April } \\
1992\end{array}$ & July & Sept & $\begin{array}{c}\text { Jan } \\
1993\end{array}$ & April & July & Sept & $\begin{array}{c}\text { Jan } \\
1994\end{array}$ & April & July & Sept & Jan & April & July \\
\hline & & & & & & & & & & & & & \\
\hline
\end{tabular}


Fig. 2 Flow of participants, combined over both phases of the study

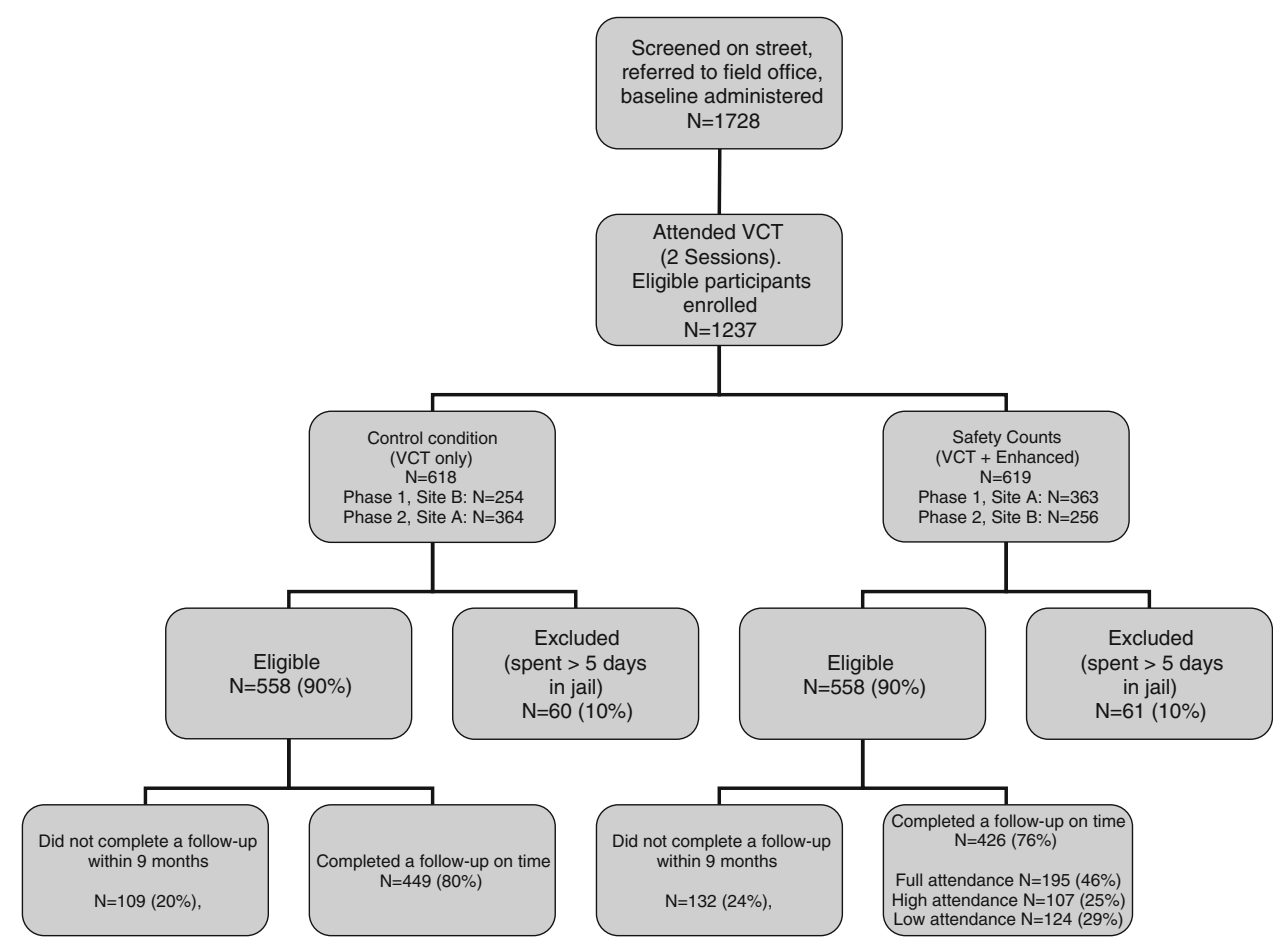

B received the Safety Counts intervention, and those in Site A received only VCT. Separate groups of participants were enrolled in each phase of the study; cross-over of treatment occurred by neighborhood, but not by individual.

Figure 2 describes the participant flow through the study. Some otherwise eligible participants were excluded from the analyses if their responses to the baseline or follow-up interview indicated that they had been jailed for more than five of the previous 30 days $(n=121,10 \%)$. Being jailed reduces the individual's autonomy in choosing to engage in sexual and drug use behaviors. In order to accurately evaluate behavioral changes in response to the interventions, we excluded such jailed participants.

\section{Assessments}

The baseline and follow-up assessments were similar and administered by interviewers based in the field office. Interviewers were ethnically diverse and well trained; the quality of the interviews was supervised on an ongoing basis. In addition to these interviews, urine samples were collected. Urine was tested for the presence of cocaine and heroin, using OnTrak [26]. These tests can detect indicators of heroin and indicators of cocaine for about 2-3 days after use. "Recent" drug and sexual risk behaviors are defined as occurring in the 30 days prior to the assessment for selfreport measures.

\section{Sexual Risk Acts}

Participants reported the recent number of vaginal and anal sexual acts performed, and condom use per sexual act. From these reports, we constructed counts of the number of vaginal and anal sexual acts, and the number of these sexual acts that were unprotected. Safer sex was defined as $100 \%$ condom use or abstinence.

\section{Substance Use}

Participants reported use of the following substances: alcohol, marijuana, crack, cocaine, heroin, speedball, nonprescription methadone, other opiates, amphetamines, and other drugs. Total times used as well as times injected in the past month were ascertained. From these reports, we constructed counts of times having injected any substance, and times having used crack. For injection drug use, participants also reported the number of times they injected with dirty works (needles/syringes) that had not been cleaned with bleach. We also constructed counts of the number of times having used alcohol or marijuana, and number of times having used drugs other than alcohol or marijuana (via any method). As noted above, we obtained urine samples for each participant at the baseline and follow-up assessments which were tested for crack/cocaine and opiate metabolites. 


\section{Demographic Characteristics}

Age, gender, ethnicity, education, marital status, employment and housing status, HIV status, and days incarcerated were reported at each interview.

\section{Intervention Conditions}

Participants completing the two VCT sessions were included in the study regardless of HIV status. Thus, there were both HIV + and HIV - participants in both conditions. Depending upon the site and phase of the study, participants were assigned to either the control (VCT only) or Safety Counts condition.

\section{Control Condition: VCT Only}

VCT was conducted in a one-on-one setting by trained counselors in a field office. The initial counseling session was didactic and based on the NIDA Standard Intervention, outlining the benefits and risks of HIV testing, drug use, and sexual risk. All participants accepted the HIV test that was offered to them. A second post-HIV test session was also conducted in an individual setting, at which time HIV test results were delivered, and additional information was provided regarding strategies for reducing sexual and drugrelated risks.

\section{Safety Counts: VCT Plus Seven Sessions/Activities}

The enhanced intervention consisted of the two VCT sessions outlined above plus the following activities: two small-group, skill-focused workshops and one individual counseling session. In addition, participants were expected to engage in at least two structured contacts conducted by outreach workers in street hang-outs, focusing on providing support to participants for achieving personal risk reduction goals. Finally, participants were expected to attend at least two of the monthly social events provided for participants and their invited guests. It took four months for the participants to complete this intervention sequence. High participation in Safety Counts was considered to be a total of at least five sessions or activities (two workshops plus the individual counseling session in the office and at least two additional activities, either outreach contacts or social events).

The two small-group workshops focused on skillbuilding at which participants were presented with role model vignettes [27] and strategies for reducing sexual and drug use actions, and were asked to commit to changing a specific sexual or drug use risk reduction behavior. Participants wrote risk reduction goals on cards kept by both the outreach workers and the participants.
The two workshops were followed by an individual counseling session delivered in the field office to plan how to implement the risk reduction goals. Street outreach workers followed up at least two times on the planning and implementation of the goals during street contacts.

The social events were held monthly for all participants and included a meal, risk-reduction games and skits, personal testimonials, and recognition of participants' progress in achieving their personal risk reduction goals.

Four to six ethnically diverse outreach workers delivered the intervention. Outreach workers were similar to participants in ethnicity and many were themselves former drug users, familiar with patterns of daily drug use. Outreach workers received extensive training prior to intervention delivery. First, there was educational training on HIV, transmission risks, and protective behaviors, as well as the theory of behavior change and the Prochaska theory of change [8]. Second, street outreach workers were provided scripts that demonstrated the intervention in role play and with mock clients. Both the individual and the small group sessions were modeled for and practiced by the outreach workers. Finally, outreach workers demonstrated their intervention skills with drug users in the field, accompanied by a supervisor who critiqued their skills.

Participants were compensated $\$ 10$ for participation in the baseline interview, $\$ 10$ for additional assessments at the second VCT session, and $\$ 20$ for participation in the follow-up interview. Non-monetary incentives included food coupons, bus tokens, and personal hygiene kits that were provided at intervention sessions. Other non-monetary incentives included meals at social events, snacks at the intervention workshops, and drawings with prizes.

\section{Data Analyses}

Chi-square and ANOVA tests were used to compare baseline characteristics of participants: completing both assessments versus lost to follow-up, assigned to the Safety Counts condition versus assigned to the VCT condition, lost to follow-up in the Safety Counts condition versus lost to follow-up in the VCT condition, and jailed more than five days in the Safety Counts condition versus jailed in the VCT condition.

Crack cocaine or injecting drug use were criteria for participation in this study. We evaluated the effectiveness of the Safety Counts intervention in stopping each behavior, using logistic regression. Separate models were used to estimate the probabilities of stopping crack use among those reporting crack use at baseline and for stopping injection drug use among IDU at baseline.

We compared drug users in the Safety Counts and the VCT condition on counts of risky sexual behaviors, counts of drug use, the probability of practicing safe sex (being 
abstinent or using condoms at all times), and the probability of having clean urinalysis results for cocaine and opiates using generalized linear mixed-effects models (GLMM). Each participant's self-reported count was modeled as a Poisson distribution with a log link and a random intercept. Practicing safe sex or having a clean urinalysis was modeled in a logistic analysis with a random intercept. Baseline and follow-up assessments had separate means in the intervention and control conditions. To test for differences between Safety Counts and the VCT control conditions, we evaluated the statistical significance of a treatment-by-time interaction.

The treatment-by-time effect estimated in our Poisson models for count variables is, when exponentiated, a measure of the additional change in the outcome measure from baseline to follow-up that is attributable to Safety Counts. It is equivalent to the ratio: phases (pre and post crossover), we reran all analyses controlling for site and phase. Results were unchanged, and we present results from the simpler models.

Finally, as noted above, we compared baseline characteristics of participants assigned to the VCT and Safety Counts arms of the study. We found one characteristic where there was a significant difference (unemployment, $P<0.05$ ), and reran the models controlling for that characteristic. The results did not differ, and findings are shown without this variable in the model.

SAS Proc GLIMMIX (GLIMMIX 9.1 add-on procedure, June 2006 release, SAS Institute, Cary, NC) was used to fit the models. We duplicated the analysis using WinBUGS [27], a Bayesian modeling program that uses Markov chain Monte Carlo computing. We used uninformative but proper priors; results were generally similar to GLIMMIX. Therefore, we present only the GLIMMIX results here.

(Predicted mean count, treated condition at follow-up/Predicted mean count, treated condition at baseline)

(Predicted mean count, control condition at follow-up/Predicted mean count, control condition at baseline)

If the change from baseline to follow-up is the same for both groups, this ratio would be 1 . Values less than 1 indicate that the participants in the Safety Counts condition reduced more than the VCT condition (e.g., 0.5 reflects twice as much change in Safety Counts compared to VCT).

The treatment-by-time effect in the logistic models for binary outcomes (negative urine tests for opiates and cocaine, practicing safe sex) is, when exponentiated, a measure of the increased odds of the outcome occurring at follow-up due to Safety Counts. It is equivalent to the ratio:

\section{Results}

Sample Description

As shown on Fig. 2, 1,728 individuals were identified through street outreach and received the initial baseline interview. From that group, 1,237 (72\%) had their drug use confirmed by way of visible track marks or positive urine screens, and completed both VCT sessions; these individuals were enrolled in the study. One hundred twenty-one

(Odds of outcome occurring, treated condition at follow-up/Odds of outcome occurring, treated condition at baseline (Odds of outcome occurring, control condition at follow-up/Odds of outcome occurring, control condition at baseline

To test the sensitivity of our findings to extreme values, we reran the mixed-effects models of count variables, omitting both baseline and follow-up observations for participants with unusually high baseline measures. Participants were omitted if their baseline measure was in the top $1 \%$ of observations; this resulted in dropping 11 participants from the analysis. Estimates of treatment effect ratios and significance did not change in any important way, and we report only the complete data analysis.

In addition, to determine whether there might be any effects on our findings caused by the groupings of observations into two locations (Sites A and B) and two study enrolled participants (61 VCT, 60 Safety Counts) were excluded from analysis due to having been jailed for more than five days in the month prior to either assessment. There were no significant differences in background characteristics by study arm among those who were excluded due to incarceration. This exclusion resulted in a final sample of 1,116, with 558 in the VCT condition and 558 in the Safety Counts condition, as shown in Fig. 2.

Except where noted, all participants were included in our analyses; however, we did not have complete follow-up data. Across both study conditions, 241 eligible participants did not complete the follow-up within the window of 
five to nine months after the baseline interview (213 not returned at all, 28 returned too late). The follow-up rate was $80 \%$ among those assigned to VCT, and $76 \%$ among those receiving Safety Counts. Among those with timely follow-ups, the mean length of time from the baseline to follow-up interview was 186 days ( $\mathrm{SD}=36$ days), about 18 days longer in the Safety Counts condition compared to the VCT condition.

We analyzed the differences between eligible participants who did and did not complete a follow-up on time (complete results available from the authors). Participants lost to follow-up were significantly more likely to be male (76 vs. $65 \%$ ), White (43 vs. $27 \%$ ), younger (36 vs. 39 years old; $20 \%$ under the age of 30 years vs. $12 \%$ ), never married (46 vs. 37\%), less educated (high school education or less: 83 vs. $74 \%$ ), or homeless (51 vs. $40 \%$ ). They were more likely to use both crack and injection drugs, in contrast to only one or the other substance (44 vs. $33 \%$ ), to have had a positive urine screen for opiates (60 vs. 44\%), and to have injected more times in the last 30 days (61 vs. 42 times). Sexual behavior, HIV status, crack use, sharing needles, and employment did not differ significantly between those analyzed and those lost to follow-up. If a significant difference emerged on sociodemographic characteristics, we compared those without follow-ups between the VCT and Safety Counts conditions. There were no significant differences between these two groups.

Table 2 summarizes the baseline demographic and risk behavior profiles of the participants in the Safety Counts and the VCT conditions. Similar across conditions, participants were mostly male (67\%); unpartnered (74\%); predominantly African American (44\%), White (30\%), and Latino (20\%); and had a mean age of 38 years old (range 18-65 years old). Most had a high school education or less (76\%), 43\% were homeless, and $4 \%$ were identified as $\mathrm{HIV}+$, again, similar across conditions. Overall, $88 \%$ were unemployed, with slightly more in the VCT condition than in Safety Counts (90 vs. 85\%, $P<0.05$ ).

Risk behaviors at baseline were similar across conditions with one exception: the number of times using crack was higher (47 vs. 39 times in the last 30 days) among the Safety Counts participants in contrast to those in the VCT condition. There were three subgroups of drug users: $30 \%$ were injectors only, 35\% used only crack, and 35\% were both heroin injectors and crack users. On average, $28 \%$ of IDU used dirty works (needles/syringes) during the last month; participants used dirty works about 4.9 times in the last month, but there was a large variance on the number of uses of a dirty needle.

Positive urinalysis results for cocaine were found at baseline among $85 \%$ of participants and $47 \%$ were positive for heroin. About $70 \%$ were sexually active in the last 30 days, with a mean of 10 sexual acts; only $25 \%$ of sex acts were protected by condoms. Among those who were sexually active, $66 \%$ had never used a condom in the past month.

\section{Sex and Drug Outcomes Across Intervention Conditions Over Time}

Logistic regressions were used to examine the effect of the Safety Counts intervention on the likelihood of stopping injection drug use among the 537 participants with followups who were IDU at baseline, and on the likelihood of stopping use of crack among the 622 participants with follow-ups using crack at baseline [not shown]. Among baseline IDU in the Safety Counts condition, 31\% (80/258) reported no injection drug use at follow-up, compared to $23 \%(63 / 279)$ among participants in VCT (estimated OR $=1.6, P=0.02)$. Twenty-nine percent (89/302) of baseline crack users in the Safety Counts condition reported no crack use at follow-up, which was not significantly different from the $27 \%$ rate $(85 / 320)$ found among baseline crack users in VCT.

Table 3 summarizes the rates of risk behaviors at baseline and follow-up, and provides the results of random effects analyses, modeling counts with a Poisson distribution, and using a logistic model for practicing safe sex and for having clean urinalysis results. The Safety Counts intervention resulted in significantly greater reductions in the numbers of sexual acts (ratio $=0.78, P<.001$ ), unprotected sexual acts (ratio $=0.58, P<.001$ ), times injecting (ratio $=0.93, P<.001$ ), times injecting with dirty works (ratio $=0.51, P<.001$ ), times using crack (ratio $=0.90, P<.001$ ), and times using drugs other than alcohol or marijuana (ratio $=0.93, P<.001$ ). On only one measure did those in the Safety Counts condition tend to show less reduction over time than those in the VCT condition: use of alcohol or marijuana (ratio $=1.03$, $P=0.14)$. The logistic analyses of urinanalysis results and practicing safer sex did not show any significant differences between the Safety Counts and VCT conditions.

\section{High Participation}

Participants in Safety Counts who demonstrated high adherence to the intervention (participating in five or more intervention activities) showed greater improvement than did those who participated less. For those outcomes where there was a significant intervention effect in the intentionto-treat analyses, Table 4 reports the decreases in risky behaviors among those with low participation in Safety Counts versus high participation. With the exception of number of sexual acts, in which those with less participation showed a slightly greater reduction, decreases in risky behaviors are, overall, markedly greater among those who have better attendance at intervention events. 
Table 2 Baseline characteristics of the sample grouped by intervention condition
* Indicates Chi-square or $t$-test $P$-value $<0.05$

* Sum of times injected: cocaine, heroin, speedball, nonprescription methadone, other opiates, amphetamines, other drugs; plus different occasions used without injecting: crack, cocaine, heroin, speedball, nonprescription methadone, other opiates, amphetamines, other drugs

\begin{tabular}{|c|c|c|c|}
\hline & VCT & Safety Counts & Total \\
\hline Number of participants & 558 & 558 & 1,116 \\
\hline Completed a follow-up on time, $N(\%)$ & $449(80.5)$ & $426(76.3)$ & $875(78.4)$ \\
\hline Male, $N(\%)$ & $384(68.8)$ & $367(65.8)$ & $751(67.3)$ \\
\hline African American, $N(\%)$ & $243(43.5)$ & $248(44.4)$ & $491(44.0)$ \\
\hline White, $N(\%)$ & $169(30.3)$ & $169(30.3)$ & $338(30.3)$ \\
\hline Latino, $N(\%)$ & $124(22.2)$ & $102(18.3)$ & $226(20.3)$ \\
\hline Other race/ethnicity, $N(\%)$ & $22(3.9)$ & $39(7.0)$ & $61(5.5)$ \\
\hline Age, mean (SD) & $38.1(8.3)$ & $38.1(7.6)$ & $38.1(7.9)$ \\
\hline$<30, N(\%)$ & $84(15.1)$ & $71(12.7)$ & $155(13.9)$ \\
\hline $30-34, N(\%)$ & $105(18.8)$ & $104(18.6)$ & $209(18.7)$ \\
\hline $35-39, N(\%)$ & $147(26.3)$ & $158(28.3)$ & $305(27.3)$ \\
\hline $40-44, N(\%)$ & $109(19.5)$ & $123(22.0)$ & $232(20.8)$ \\
\hline $45+, N(\%)$ & $113(20.3)$ & $102(18.3)$ & $215(19.3)$ \\
\hline Less than HS graduate, $N(\%)$ & $232(41.7)$ & $231(41.4)$ & $463(41.5)$ \\
\hline HS graduate or GED, $N(\%)$ & $197(35.4)$ & $189(33.9)$ & $386(34.6)$ \\
\hline Some college, $N(\%)$ & 98 (17.6) & $106(19.0)$ & $204(18.3)$ \\
\hline College graduate or more, $N(\%)$ & $30(5.4)$ & $32(5.7)$ & $62(5.6)$ \\
\hline Single, never married, $N(\%)$ & $209(37.5)$ & $26(40.5)$ & $435(39.0)$ \\
\hline Married, living with spouse, $N(\%)$ & $153(27.4)$ & $142(25.4)$ & $295(26.4)$ \\
\hline Widowed, separated, divorced, $N(\%)$ & $196(35.1)$ & $190(34.1)$ & $386(34.6)$ \\
\hline Currently unemployed, $N(\%)$ & $498(89.6)$ & $475(85.4)$ & $973(87.5)^{*}$ \\
\hline Currently homeless, $N(\%)$ & $251(45.1)$ & $224(40.3)$ & $475(42.7)$ \\
\hline HIV negative, $N(\%)$ & $516(92.5)$ & $515(92.3)$ & $1,031(92.4)$ \\
\hline HIV positive, $N(\%)$ & $18(3.2)$ & $25(4.5)$ & $43(3.9)$ \\
\hline Serostatus unknown, $N(\%)$ & $24(4.3)$ & $18(3.2)$ & $42(3.8)$ \\
\hline Injection drug user only, $N(\%)$ & $167(29.9)$ & $162(29.0)$ & $329(29.5)$ \\
\hline Crack user only, $N(\%)$ & $194(34.8)$ & $199(35.7)$ & $393(35.2)$ \\
\hline Both IDU and crack user, $N(\%)$ & $197(35.3)$ & $197(35.3)$ & $394(35.3)$ \\
\hline Cocaine in urine at baseline, $N(\%)$ & $463(83.6)$ & $483(86.7)$ & $946(85.1)$ \\
\hline Opiates in urine at baseline, $N(\%)$ & $260(46.7)$ & $266(47.7)$ & $526(47.2)$ \\
\hline \multicolumn{4}{|l|}{ In the 30 days prior to baseline } \\
\hline Sexually active, $N(\%)$ & $396(71.0)$ & $380(68.1)$ & $776(69.5)$ \\
\hline Times had sex, mean (SD) & $10.2(23.1)$ & $9.6(18.3)$ & $9.9(20.9)$ \\
\hline Number of unprotected sex acts, mean (SD) & $7.3(15.1)$ & $7.2(15.6)$ & $7.2(15.4)$ \\
\hline Practiced safe sex, $N(\%)$ & $240(43.0)$ & $235(42.1)$ & $475(42.6)$ \\
\hline Times injected drugs, mean (SD) & $46.5(61.6)$ & $46.1(59.0)$ & $46.3(60.3)$ \\
\hline Times injected with dirty works, mean (SD) & $4.7(20.4)$ & $5.1(20.8)$ & $4.9(20.6)$ \\
\hline Times used crack, Mean (SD) & $38.6(56.2)$ & $46.7(70.8)$ & $42.7(64.0)^{*}$ \\
\hline Times used alcohol or marijuana, mean (SD) & $35.5(59.4)$ & $32.8(51.4)$ & $34.2(55.5)$ \\
\hline Times used other drugs ${ }^{*}$, Mean (SD) & $95.5(111)$ & $99.4(85.6)$ & $97.5(99.3)$ \\
\hline
\end{tabular}

\section{Discussion}

In contrast to the Hershberger et al. [28] analyses, we found that Safety Counts results in substantial reductions in both sex and drug use. Hard drug users, those actively using crack or injecting drugs in the past month, demonstrated significant reductions in sex and drug use risk acts after receiving the Safety Counts intervention. The effect sizes are relatively large and the greatest reductions are in the types of behavior most likely to result in HIV transmission: unprotected sexual acts and injection with dirty works. Almost all evidencebased HIV-related interventions have been based on a social cognitive approach to behavior change [19] in which change occurs slowly over time in small steps, in response to opportunity and social rewards. Drug users in the Safety Counts condition were much more likely to stop injecting 
Table 3 Observed values at each assessment by safety counts or VCT
Estimated effect sizes and significance

* Estimated effect size $=\left(\mathrm{SC}_{\mathrm{FU}} / \mathrm{SC}_{\mathrm{BL}}\right) /\left(\mathrm{VCT}_{\mathrm{FU}} /\right.$ $\mathrm{VCT}_{\mathrm{BL}}$ ) where $\mathrm{SC}$ and VCT indicate Safety Counts and VCT, respectively

$\mathrm{BL}$ and $\mathrm{FU}$ indicate values at baseline and follow-up, respectively. For outcomes measured as counts, the values represented by SC and VCT are means. For binomial outcomes, the values represented by SC and VCT are odds

\begin{tabular}{|c|c|c|c|c|c|}
\hline & \multicolumn{2}{|c|}{ Observed mean or percent } & \multicolumn{3}{|c|}{ Results from mixed-effects models } \\
\hline & $\begin{array}{l}\text { Baseline } \\
(N=1,116)\end{array}$ & $\begin{array}{l}\text { Follow-up } \\
(N=875)\end{array}$ & $\begin{array}{l}\text { Estimated } \\
\text { effect size }\end{array}$ & $\begin{array}{l}\text { Model } \\
t \text {-statistic }\end{array}$ & $\begin{array}{l}\text { Significance } \\
\text { of effect }\end{array}$ \\
\hline \multicolumn{6}{|c|}{ Counts of risky behaviors } \\
\hline \multicolumn{6}{|c|}{ Number of sex acts } \\
\hline VCT & 10.21 & 9.29 & 0.78 & 7.76 & $<0.001$ \\
\hline Safety counts & 9.61 & 7.28 & & & \\
\hline \multicolumn{6}{|c|}{ Number of unprotected sex acts } \\
\hline VCT & 7.26 & 7.23 & 0.58 & 14.22 & $<0.001$ \\
\hline Safety counts & 7.15 & 4.50 & & & \\
\hline \multicolumn{6}{|c|}{ Times injected drugs } \\
\hline VCT & 46.5 & 34.5 & 0.93 & 4.36 & $<0.001$ \\
\hline Safety counts & 46.1 & 31.7 & & & \\
\hline \multicolumn{6}{|c|}{ Times injected drugs with dirty works } \\
\hline VCT & 4.66 & 3.87 & 0.51 & 12.56 & $<0.001$ \\
\hline Safety Counts & 5.08 & 1.85 & & & \\
\hline \multicolumn{6}{|c|}{ Times used crack } \\
\hline VCT & 38.6 & 21.6 & 0.90 & 6.01 & $<0.001$ \\
\hline Safety counts & 46.7 & 23.4 & & & \\
\hline \multicolumn{6}{|c|}{ Times used alcohol or marijuana } \\
\hline VCT & 35.5 & 23.0 & 1.03 & 1.49 & 0.14 \\
\hline Safety counts & 32.8 & 22.8 & & & \\
\hline \multicolumn{6}{|c|}{ Times used other drugs } \\
\hline VCT & 95.5 & 62.9 & 0.93 & 6.25 & $<0.001$ \\
\hline Safety counts & 99.4 & 60.2 & & & \\
\hline \multicolumn{6}{|c|}{ Binomial outcomes } \\
\hline \multicolumn{6}{|c|}{ Had a negative urine test for cocaine } \\
\hline VCT & $16 \%$ & $26 \%$ & 1.51 & 1.73 & 0.08 \\
\hline Safety counts & $13 \%$ & $29 \%$ & & & \\
\hline \multicolumn{6}{|c|}{ Had a negative urine test for opiates } \\
\hline VCT & $53 \%$ & $60 \%$ & 1.09 & 0.42 & 0.68 \\
\hline Safety counts & $52 \%$ & $61 \%$ & & & \\
\hline \multicolumn{6}{|c|}{ Practiced safe sex } \\
\hline VCT & $43 \%$ & $54 \%$ & 1.19 & 0.92 & 0.36 \\
\hline Safety counts & $42 \%$ & $57 \%$ & & & \\
\hline
\end{tabular}

than those in the VCT: $35 \%$ more stopped injecting completely. Abstinence from injecting is a substantial shift in behavior. In addition to stopping IDU, there were significantly greater reductions over time in the number of times injecting, injecting with dirty works, and the number of times of using crack in the last month (ratios $=0.51-0.93$ ). These differences are important among serious drug users.

Simultaneous to stopping or reducing drug use, there were also significant reductions in the amount of sexual activity overall, and the number of unprotected sex acts. While only $4 \%$ of the participants were known to be HIV + in the sample, many communities of IDU have much higher rates. Combined with the reductions in injection use, the reductions in sexual risk are also substantial (ratios $=0.58-0.78$ ).
An important aspect of the program was its simultaneous focus both on personal tailoring and the communitylevel outreach. Counseling at the workshops and individual sessions were adapted to the individual's risk background. However, the street outreach targeted a neighborhood, and the social activities were aimed at building social networks within the community. Many interventions have been labeled "individual," "family," or "community" level. Yet, each individual intervention has a site or institutional component, and every successful community-level intervention has also included training individuals to be more efficacious in their personal lives. Safety Counts targets hang-out spots in communities with high rates of drug use. Since the beginning of the HIV epidemic, geography has 
Table 4 Decreases in risky behaviors from baseline to follow-up by level of participation in the Safety Counts program

\begin{tabular}{lll}
\hline & Low participation $(N=124)(\%)$ & High or full participation $(N=302)(\%)$ \\
\hline Percentage decrease from baseline to follow-up & 30 & 25 \\
Times had sex & 24 & 46 \\
Times had unprotected sex & 9 & 32 \\
Times injected & 28 & 62 \\
Times injected with used, uncleaned works & 44 & 55 \\
Times used crack & 26 & 43 \\
Times used other drugs & Low participation $(N=77)(\%)$ & High or full participation $(N=181)(\%)$ \\
\hline & \\
\hline Percent of users at baseline who stop using at follow-up & 33 \\
Injection drug use & 27 &
\end{tabular}

Analysis limited to Safety Counts participants completing a follow-up assessment $(N=426)$. High participation is defined as attending the first three intervention sessions plus two or more of the remaining events; full participation is defined as attending all seven possible sessions or events. The remaining participants are classified as having low participation

* Percentage decrease calculated as: $100\left(\mathrm{BL}_{\mathrm{P}}-\mathrm{FU}_{\mathrm{P}}\right) / \mathrm{BL}_{\mathrm{P}}$, where $\mathrm{BL}$ and $\mathrm{FU}$ indicate baseline and follow-up mean, and $P$ indicates the low participation or high participation group over which the mean is calculated

been destiny [9]; this intervention provides a packaged solution based on local epidemiology of HIV.

It is not possible to identify which are the components of the Safety Counts intervention most responsible for changing habitual risk behaviors. Skill-building workshops, goal setting in one-on-one counseling sessions, street contacts and social events were all included in Safety Counts. These are common elements in many evidencebased interventions [25, 29]. Future research must identify which components of the intervention are most effective in reducing the risk behaviors of active drug users.

\section{Limitations}

This study's significant results rely on self-reports. No significant treatment effects were found in urine screens for heroin and cocaine. However, the metabolites of heroin and cocaine only represent a sample of use in the last three days. In addition, several significant intervention effects were found that involved reduction rather than elimination of risky behaviors; such reductions may not have been reflected in urinalysis results, which test for any use. Considerable effort was made to obtain reliable self-reports from participants at both the baseline and the follow-up assessments, and the interviewers and the street outreach workers were different.

The follow-up rate was 78\%, an acceptable rate for such a high-risk target population, but not optimal. The participants who were lost to follow-up were even riskier than the participants that we were able to follow successfully and reassess. It is not clear whether this led to us assessing those most or least likely to change over time in response to the intervention.
One outcome measure differed significantly by treatment arm at baseline: times used crack. Safety Counts participants demonstrated both greater use at baseline (47 vs. 38 times used crack) and significantly greater improvement over the course of the study than did those in VCT only. Some of the greater improvement may be attributable to Safety Counts participants experiencing more regression to the mean, as they started out at higher baseline levels.

We chose to exclude those who were in jail for five or more days prior to either the baseline or the follow-up interview. Therefore, we define our population of interest to be the non-incarcerated. Because of similarities across intervention arm in the number and characteristics of those excluded, there is little bias anticipated due to exclusion of the incarcerated.

It is notable that this study was conducted in West Coast communities, neighborhoods with much larger geographic areas, less density than the drug neighborhoods along the East Coast of the United States that have much higher rates of HIV infection [3]. Safety Counts, available from the CDC (www.effectiveinterventions.org), may be useful in communities with street hang-outs that facilitate injection use by networks of persons at high-risk for HIV.

Street outreach is a community-level intervention program, with individually tailored components included within the community model. It would have been desirable to gather evaluation data at the level of the community rather than the individual. In particular, the social activities created an opportunity for community members to gather, to set norms that oppose drug use and unprotected sex, and to foster relationships that build community social capital. However, we evaluated the program at the level of the 
individual participants. Given that there were only two sites, we could not use site as the unit of analysis.

It is noteworthy that the results of these analyses are different from those presented in the 2003 paper of Hershberger and colleagues. While that analysis found some significant intervention effects, it was far fewer than the current analytic strategy demonstrated. The primary differences between our findings and theirs are attributable to the choice of inclusion criteria, outcome measures, and statistical methods. The contrasting findings point to the importance of the decisions made when conducting data analyses. This is problematic for researchers. It is seldom that the same data set is examined by more than one team. The fact that our findings differ points to the importance of taking more than one look at a given research question.

This study identifies an intervention approach that can result in successful reduction of drug use and sexual risktaking in a targeted community, a key strategy for the next generation of preventive interventions. It is being broadly implemented through the CDC DEBI programs currently. The next generation of outcome analyses will indicate whether the benefits are sustained as Safety Counts is adopted at the local level.

Acknowledgments This paper was completed with the support of National Institute of Health grants \# R18-DA05747, U01-DA07474, 1ROI MH49958-04 and P30 MH58107.

Open Access This article is distributed under the terms of the Creative Commons Attribution Noncommercial License which permits any noncommercial use, distribution, and reproduction in any medium, provided the original author(s) and source are credited.

\section{References}

1. Steele CB, Melendez-Morales L, Campoluci R, DeLuca N, Dean HD. Health disparities in HIV/AIDS, viral hepatitis, sexually transmitted diseases, and tuberculosis in the United States: issues, burden, and response, a retrospective review, 2000-2004. Atlanta: Department of Health and Human Services, Centers for Disease Control and Prevention; 2007.

2. Mathers BM, Degenhardt L, Phillips B, et al. Global epidemiology of injecting drug use and HIV among people who inject drugs: a systematic review. Lancet. 2008;372:1733-45.

3. Centers for Disease Control. Morbidity and mortality weekly report, October 3, 2008: HIV prevalence estimates-United States. 2006. Available at: www.cdc.gov/mmwr/preview/mmwr $\mathrm{html} / \mathrm{mm} 5739 \mathrm{a} 2 . \mathrm{htm}$. Accessed 23 Dec 2008.

4. Substance Abuse and Mental Health Services Administration, Office of Applied Studies. Results from the 2007 National Survey on Drug Use and Health: National findings. Rockville. 2008. [NSUDH Series H-34, DHHS Publication No. SMA 08-4343, Table G.3].

5. Edlin BR, Irwin KL, Faruque $\mathrm{S}$, et al. Intersecting epidemicsCrack cocaine use and HIV infection among inner-city young adults. NEJM. 1994;331(21):1422-7.

6. Des Jarlais DC, Dehne K, Casabona J. HIV surveillance among injecting drug users. AIDS. 2001;15(suppl 3):S13-22.
7. Strathdee SA, Patterson TL. Behavioral interventions for HIVpositive and HCV-positive drug users. AIDS Behav. 2006;10(2): 115-30.

8. CDC AIDS Community Demonstration Projects Research Group. Community-level HIV intervention in 5 cities: final outcome data from the CDC AIDS Community Demonstration Projects. Am J Public Health. 1999;89(3):336-45.

9. Rotheram-Borus MJ, Koopman C. HIV and adolescents. J Prim Prev. 1991;2(1):65-82.

10. Bloom HS, editor. Learning more from social experiments: evolving analytic approaches. New York: Sage; 2006.

11. Murdoch J. Post-structuralist geography: a guide to relational space. London: Sage; 2006.

12. Friedman SR, Curtis R, Neaigus A, Jose B, Des Jarlais DC. Social networks, drug injectors' lives, and HIV/AIDS. New York: Springer Publications; 1999.

13. Latkin C, Mandell W, Oziemkowska M, et al. Using social network analysis to study patterns of drug use among urban drug users at high risk for HIV/AIDS. Drug Alcohol Depend. 1995;38:1-9.

14. Christakis NA, Fowler JH. The collective dynamics of smoking in a large social network. NEJM. 2008;358:2249-58.

15. Murray DM, McKinlay SM, Martin D, et al. Design and analysis issues in community trials. Eval Rev. 1994;18(4):493-514.

16. Boruch RF, Foley E. The honestly experimental society: using organization and other entities as units in randomized experiments. In: Bickman L, editor. Donald F. Campbell's legacy. Thousand Oaks: Sage; 2000.

17. Prochaska JO, DiClemente CC. Stages and processes of selfchange of smoking: toward an integrative model of change. J Consult Clin Psychol. 1983;51:390-5.

18. Prochaska JO, DiClemente CC. Toward a comprehensive model of change. In: Miller WR, Heather N, editors. Treating addictive behaviors: processes of change. New York: Plenum Press; 1986.

19. Bandura A. Social foundations of thought and action: a social cognitive theory. Englewood Cliffs: Prentice Hall; 1986.

20. Becker MH. The health belief model and personal health behavior. Health Educ Monogr. 1974;2:324-508.

21. Maddux JE, Rogers RW. Protection motivation and self-efficacy: a revised theory of fear appeals and attitude change. J Exp Soc Psychol. 1983;19:469-79.

22. Centers for Disease Control, Division of HIV/AIDS Prevention. Safety counts: a cognitive-behavioral intervention to reduce HIV/ Hepatitis risks among drug users who are not in drug treatmentprogram manual. Washington, DC: Academy for Educational Development; 2003. revised 2007.

23. Rhodes F, Humfleet GL. Using goal-oriented counseling and peer support to reduce HIV/AIDS risk among drug users not in treatment. Drugs Soc. 1993;7:185-204.

24. Coyle S. The NIDA HIV counseling and education intervention model: intervention manual (NIH Pub. No. 93-3508). Rockville: National Institute on Drug Abuse; 1993.

25. Rotheram-Borus MJ, Swendeman D, Flannery D, Rice E, Adamson DM, Ingram B. Common factors in effective HIV prevention programs. AIDS Behav. 2009;13(3):399-408.

26. Varian, Inc. Diagnostic products. 2009. Available at: http://www. varianinc.com/cgi-bin/nav?products/dat/index\&cid=KMKPIHH HFJ. Accessed 5 Feb 2009.

27. Lunn DJ, Whittaker JC, Best N. A Bayesian toolkit for genetic association studies. Genet Epidemiol. 2006;30(3):231-47.

28. Hershberger S, Wood M, Fisher D. A cognitive-behavioral intervention to reduce HIV risk behaviors in crack and injection drug users. AIDS Behav. 2003;7(3):229-43.

29. Ingram BL, Flannery D, Elkavich A, Rotheram-Borus MJ. Common processes in evidence-based adolescent HIV prevention programs. AIDS Behav. 2008;12(3):374-83. 